\title{
Characterisation of Acid Resistant Concrete Exposed to Sulphuric Acid Using SEM, EDS and X-Ray Mapping
}

\author{
Shamila Salek ${ }^{1}$, Richard Wuhrer ${ }^{1}$, Georgius Adam ${ }^{2}$ and Bijan Samali ${ }^{2}$ \\ ${ }^{1}$ Advanced Materials Characterisation Facility, Western Sydney University \\ ${ }^{2}$ Centre for Infrastructure Engineering, Western Sydney University
}

Concrete, which is a widely used material in construction industry, is vulnerable to acid attack from various sources such as ground water, chemical wastes, sewage systems and acid rain. Acid attack degrades the cement in concrete which has high amount of calcium hydroxide and jeopardise the structural performance of concrete structures by eventually causing a premature failure during its expected life time. Various research works have been carried out to increase the chemical resistance of concrete. However, high cost, special curing conditions requirements and uncertainty of structural performance have raised the need for further research. In this research a novel sustainable acid resistant concrete was developed by reducing the Portland cement in concrete and its replacement with supplementary cementitious materials including fly ash, slag and silica fume as well as additions of some activators to make a hybrid concrete having commonality to conventional and geopolymer concretes. Mechanical, structural and microstructural properties of the acid resistant concrete (ARC) were evaluated and compared to conventional concrete (CC) before and after immersion in high acidic environments (13\% by weight sulphuric acid solution).

The mechanical properties and structural performance of the ARC showed quite promising results compared to conventional concrete even after eight weeks of immersion in high acidic environment in terms of loss of strength and performance. Table 1 summarises the depth of penetration of acid in ARC and CC after different periods of immersion in acid. The acid affected layer of CC is totally removed after exposure to acid. However, the ARC external layer remained intact in terms of diameter. The acid also was shown to penetrate into the ARC to a certain depth and then ceased further progression.

Characterisation analysis including scanning electron microscopy (SEM), energy dispersive spectroscopy (EDS) and X-ray mapping (XRM) were used to obtain a better understanding about the mechanism of acid attack on two types of concretes. In the XRM analysis, four main elements, calcium, silica, sulphur and iron were investigated at the interface of the acid affected and non-acid affected areas of the ARC and CC samples.

Elemental XRM image and pseudo coloured image of the acid exposed ARC sample are shown in Figure 1. The acid affected layer is rich with sulphur (Figure 1a) which is due to penetration of sulphuric acid. The $\mathrm{Ca} / \mathrm{Si} \mathrm{ratio}$ of this layer is much lower than the intact area due to decalcification of hydrated concrete phases. The pseudo coloured map reveals both calcium and sulphur (light blue area) are present that are the main elements of gypsum. Three main areas are observed in this image: Area 1 which is the acid affected layer and has not been totally decomposed. Area 2 that seems to have higher silica and area 3, which is the intact area and mostly calcium. The $\mathrm{Ca} / \mathrm{Si}$ ratio map also shows lower ratio for the affected layer compared to the intact area. This high amount of silica at the interface could be due to formation of a silica phase (geo-cement) polymer binder composed mainly of poly (aluminium silicate) three dimensional networks that acts as a barrier in ARC and prevents the aggressive agents entering the intact paste.

Figure 2 of the acid exposed CC sample reveals the acid affected layer is rich in sulphur. There is no transition zone between the acid affected and non-acid affected area and the ratio of $\mathrm{Ca} / \mathrm{Si}$ is much lower in acid affected layer due to decalcification of hydrated products in concrete such as calcium silicate hydrate, which is mainly responsible for the strength of concrete. There are four main areas observed after exposure of the CC to acid. Area 1 , which is a totally decomposed layer of the CC, breaks down and collapses due to acid attack. Area 2 that is the acid affected layer left on the sample and is rich in sulphur (dark blue), area 3 which is the interface of acid and 
non-acid affected zone and is rich in iron and finally area 4, which is the intact area and has no sulphur present. The amounts of calcium are much higher in this area compared to the affected layer [1].

\section{References:}

[1] Authors gratefully acknowledge the support of Parchem Australia Pty Ltd, Advanced Materials Characterisation facility and Centre for Infrastructure Engineering at Western Sydney University.

\begin{tabular}{ccccc}
\hline Mix reference & $\begin{array}{c}2 \text { weeks in acid } \\
(\mathrm{mm})\end{array}$ & $\begin{array}{c}4 \text { weeks in acid } \\
(\mathrm{mm})\end{array}$ & $\begin{array}{c}6 \text { weeks in acid } \\
(\mathrm{mm})\end{array}$ & $\begin{array}{c}8 \text { weeks in acid } \\
(\mathrm{mm})\end{array}$ \\
\hline CC & $6.0^{*}$ & $14.0^{*}$ & $15.0^{*}$ & $21.0^{*}$ \\
\hline ARC & 3.0 & 5.0 & 7.0 & 7.0 \\
\hline
\end{tabular}

Table 1. Acid penetration in $\mathrm{ARC}$ and *diameter reduction of $\mathrm{CC}$ after various time exposure time.

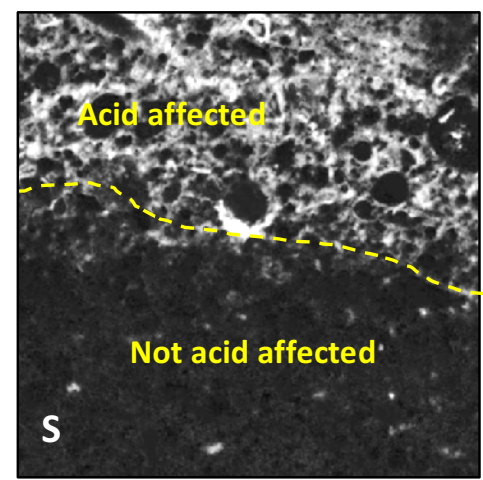

(a)

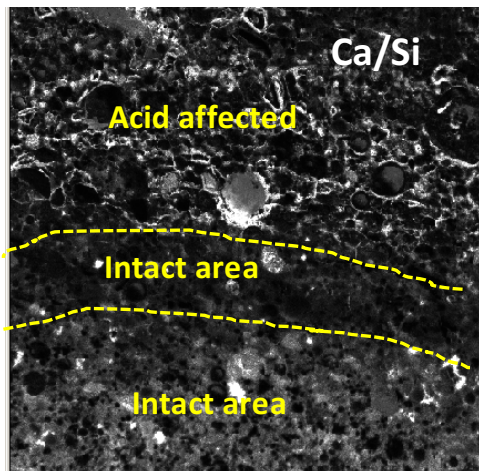

(b)

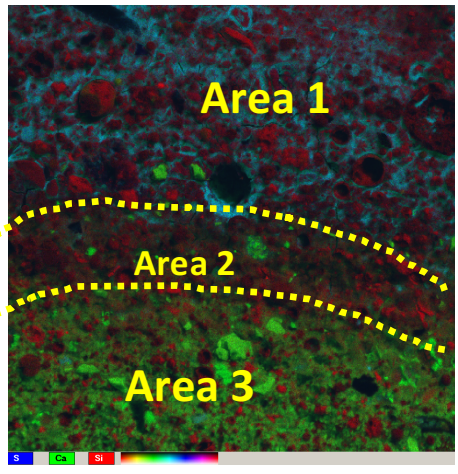

(c)

Figure 1. XRM images of $\mathrm{ARC}$ after eight weeks of exposure to $13 \%$ sulphuric acid, (a) $\mathrm{S}$ and (b) $\mathrm{Ca} / \mathrm{Si}$ ratio elements in interface of acid and non-acid affected area of specimens. The brighter area in the maps indicates more of that element present. (c) Pseudo colour X-ray map of ARC sample after eight weeks of acid exposure.

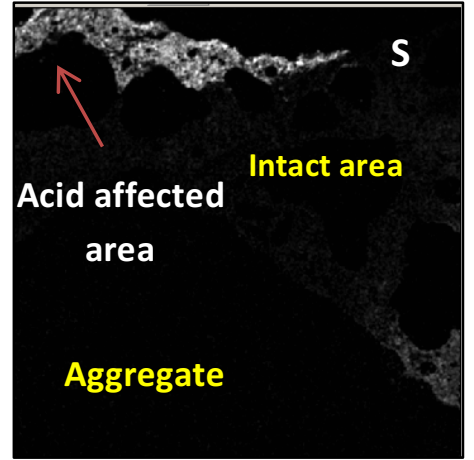

(a)

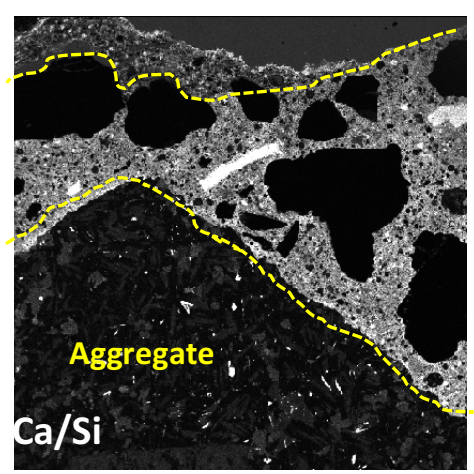

(b)

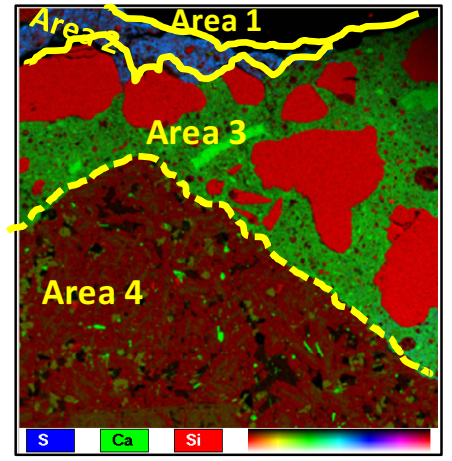

(c)

Figure 2. XRM images of CC after four weeks of exposure to $13 \%$ sulphuric acid, (a) the distribution of $\mathrm{S}$ and (b) $\mathrm{Ca} / \mathrm{Si}$ ratio elements in interface of acid and non-acid affected area of specimens. (c) Pseudo colour X-ray map of CC sample after four weeks of acid exposure. Image shows high amount of sulphur in acid affected layer and a high amount of calcium in the intact area. 